\title{
LYAPUNOV-TYPE INEQUALITIES FOR THIRD-ORDER LINEAR DIFFERENTIAL EQUATIONS
}

\author{
SOUgata DHAR AND QINGKai Kong
}

\begin{abstract}
In this paper, we obtain new Lyapunov-type inequalities for the third-order linear differential equation $x^{\prime \prime \prime}+q(t) x=0$. Our work provides the sharpest results in the literature and makes corrections to those in a recently published paper [1]. Based on the above, we further establish new Lyapunov-type inequalities for more general third-order linear differential equations. Moreover, by combining these inequalities with the "uniqueness implies existence" theorems by several authors, we establish the uniqueness and hence existence-uniqueness for several classes of boundary value problems for third-order linear equations.
\end{abstract}

Mathematics subject classification (2010): 34A40, 26D10, 34B05.

Keywords and phrases: Lyapunov-type inequalities, third-order, linear differential equations, Green's functions, boundary value problems, existence and uniqueness of solutions.

\section{REFERENCES}

[1] M. F. AKtas, D. CAKMAK, AND A. TIRYAKI, On the Lyapunov-type inequalities of a three point boundary value problem for third order linear differential equations, Appl. Math. Letters., 45 (2015), $1-6$.

[2] R. C. BRown AND D. B. Hinton, Opial's inequality and oscillation of second-order equations, Proc. Amer. Math. Soc., 125 (1997), 1123-1129.

[3] G. BorG, On a Liapunoff criterion of stability, Amer. J. Math., 71 (1949), 67-70.

[4] D. Cакмак, On Lyapunov-type inequality for a class of nonlinear systems, Math. Inq. Appl., 16 (2013), 101-108.

[5] D. CAKMAK, Liapunov-type integral inequalities for certain higher order differential equations, Appl. Math. Comput., 216 (2010), 368-373.

[6] S. DhAR AND Q. Kong, Liapunov-type inequalities for third-order half-linear equations and applications to boundary value problems, Nonlin. Anal., 110 (2014), 170-181.

[7] A. Elbert, A half-linear second order differential equation, Colloq. Math. Soc., 30 (1979), 158-180.

[8] B. J. HARRIS AND Q. Kong, On the oscillation of differential equations with an oscillatory coeffcient, Trans. Amer. Math. Soc., 347 (1995), 1831-1839.

[9] P. Hartman, Ordinary Differential Equations, Wiley, New York, 1964, and Birkhauser, Boston 1982.

[10] X. He AND X. H. TANG, Liapunov-type inequalities for even-order differential equations, Comm. Pure Appl. Math., 11 (2012), 465-473.

[11] L. K. JACKSON, Existence and uniqueness of solutions of boundary value problems for third-order differential equations, J. Diff. Eq., 13 (1973), 432-437.

[12] L. K. JACKSON, Uniqueness of solutions of boundary value problems for ordinary differential equations, SIAM J. Appl. Math., 24 (1973), 535-538.

[13] L. K. JACKSON AND K. SCHRADER, Existence and uniqueness of solutions of boundary value problems for third-order differential equations, J. Diff. Eq., 9 (1971), 46-54.

[14] J. KISEL'AK, Lyapunov-type inequality for third-order half linear differential equations, Tamkang J. Math., 44 (2013), 351-357. 
[15] M. K. Kwong, On Lyapunov inequality for disfocality, J. Math. Anal. Appl., 83 (1981), 486-494.

[16] A. M. Liapunov, Probleme general de la stabilite du mouvement, Ann. Math Stud., 17 (1947), 203 474.

[17] B. G. PachPatte, Lyapunov-type integral inequalities for certain differential equations, Georgian Math. J., 4 (1997), 139-148.

[18] B. G. PACHPATTE, On Lyapunov-type inequalities for certain higher order differential equations, J. Math. Anal. Appl., 195 (1995), 527-536.

[19] S. PANIGRAhi, Lyapunov-type integral inequalities for certain higher order differential equations, Elec. J. Diff. Eq., 2009 (2009), 1-14.

[20] N. PARHi AND S. PANigRAhi, On Liapunov-type inequality for third-order differential equations, J. Math. Anal. Appl., 233 (1999), 445-460.

[21] N. PARHI AND S. PANIGRAhi, Liapunov-type inequality for higher order differential equations, Math. Slovaca, 52 (2002), 31-46.

[22] W. T. Patula, On the distance between zeros, Proc. Amer. Math. Soc., 52 (1975), 247-251.

[23] J. P. PInASCO, Lyapunov-type inequalities with Applications to Eigenvalue Problems, Springer, 2010.

[24] A. TIRYAKI, M. UnAL, AND D. CAKMAK, Liapunov-type inequalities for nonlinear systems, J. Math. Anal. Appl., 332 (2007), 497-511.

[25] A. Wintner, On the non-existence of conjugate points, Amer. J. Math., 73 (1951), 368-380.

[26] X. YANG AND K. Lo, Liapunov-type inequality for a class of even-order differential equations, Appl. Math. Comput., 215 (2010), 3884-3890.

[27] X. YAnG, On Lyapunov inequality for certain higher-order differential equations, Appl. Math. Comput., 134 (2003), 307-317.

[28] X. YAnG, On inequalities of Lyapunov type, Appl. Math. Comput., 134 (2003), 293-300.

[29] Q. ZHANG AND X. HE, Liapunov-type inequalities for a class of even-order differential equations, J. Ineq. Appl., 2012, 2012:5. 